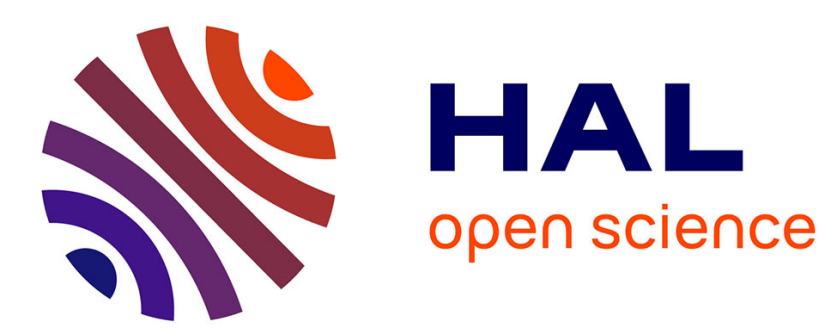

\title{
Multiple Criteria Decision Making for environmental impacts optimization
}

\author{
Ines Boufateh, Anne Perwuelz, Besoa Rabenasolo, Anne-Marie Jolly
}

\section{To cite this version:}

Ines Boufateh, Anne Perwuelz, Besoa Rabenasolo, Anne-Marie Jolly. Multiple Criteria Decision Making for environmental impacts optimization. International Journal of Business Performance and Supply Chain Modelling, 2011, 3 (1), pp.28-42. hal-00657503

\section{HAL Id: hal-00657503 https://hal.science/hal-00657503}

Submitted on 6 Jan 2012

HAL is a multi-disciplinary open access archive for the deposit and dissemination of scientific research documents, whether they are published or not. The documents may come from teaching and research institutions in France or abroad, or from public or private research centers.
L'archive ouverte pluridisciplinaire HAL, est destinée au dépôt et à la diffusion de documents scientifiques de niveau recherche, publiés ou non, émanant des établissements d'enseignement et de recherche français ou étrangers, des laboratoires publics ou privés. 


\title{
Multiple criteria decision-making for environmental impacts optimisation
}

\section{Inès Boufateh*, Anne Perwuelz and Besoa Rabenasolo}

Univ Lille Nord de France, F-59000 Lille, France

and

ENSAIT, GEMTEX,

2 allée Louise et Victor Champier, BP 30329,

59056 Roubaix Cedex 1, France

E-mail: ines.boufateh@ensait.fr

E-mail: anne.perwuelz@ensait.fr

E-mail: besoa.rabenasolo@ensait.fr

*Corresponding author

\section{Anne-Marie Jolly-Desodt}

Institut Prisme, Polytech Orléans,

8 rue Leonard de Vinci,

45072 Orléans Cedex 2, France

E-mail: anne-marie.jolly@univ-orleans.fr

\begin{abstract}
Life cycle assessment (LCA) is increasingly used as a decision support system that enables the modelling, the evaluation and the comparison of different alternatives of products, processes or supply chains as regards their environmental and sustainable impacts. In the textile-garment domain, the complexity of the supply chain adds to the difficulty of the interpretation of the LCA results. The authors' purpose is to use multiple criteria decision-making (MCDM) method in order to analyse the results of the life cycle assessment of textile products to help the different actors in the supply chain. Within this framework, the paper studies the choice of the most suitable multicriteria analysis method from the literature and shows its application in the textile supply chain.
\end{abstract}

Keywords: multiple criteria decision-making; MCDM; outranking; life cycle assessment; LCA; textile supply chain.

Reference to this paper should be made as follows: Boufateh, I., Perwuelz, A., Rabenasolo, B. and Jolly-Desodt, A-M. (2011) 'Multiple criteria decision-making for environmental impacts optimisation', Int. J. Business Performance and Supply Chain Modelling, Vol. 3, No. 1, pp.28-42.

Biographical notes: Inès Boufateh is a $\mathrm{PhD}$ student, in her final year, in the GEMTEX Laboratory (Laboratory of Genie and Textile Materials) in Roubaix, France. She obtained her Diploma of Ingénieur ENSAIT (Ecole Nationale Supérieure des Arts et Industries Textiles). Her prior experience is as a Teacher in the French Grande Ecole ENSAIT, one of the leading textile schools in Europe. Her research interest includes life cycle assessment, decision-making support systems for eco-design and textile supply chain management. She 
participated to the tutoring of students in the framework of one European project and four academic projects. She has co-authored ten papers in international and national conferences and one paper in a national journal.

\begin{abstract}
Anne Perwuelz is a full-time Professor at the ENSAIT (Ecole Nationale Supérieure des Arts et Industries Textiles) in Roubaix, France. She received her $\mathrm{PhD}$ (1983) in Material Sciences from the INSA Institute in Toulouse (F). She has been working for six years as a Researcher in the French chemical company Rhone Poulenc. In 1991, she has started her research and academic career at the ENSAIT. Her main research interests concerns physicochemical aspects in polymer engineering and in surface treatment and analysis. Environmental aspects of textile treatment has always been one of her main application and she is now also involved in life cycle analysis of textile products.
\end{abstract}

Besoa Rabenasolo is a full-time Professor at the ENSAIT (Ecole Nationale Supérieure des Arts et Industries Textiles) in Roubaix, France. He obtained his Diploma of Ingénieur IDN/Ecole Centrale de Lille in 1989. He received his MSc (1989) and PhD (1992) in Automatic Control and Computer Sciences from the University of Sciences and Technology of Lille. He received his Master of Business Management from the Institut d'Administration des Entreprises of Lille, France in 1992. His research interests include supply chain management: modelling, optimisation, and business and environmental performance management.

Anne-Marie Jolly-Desodt is the Director of Polytech'Orléans (Engineering School), Professor in the University of Orléans and member of a team of researchers in ecodesign and housing intelligence in the Prisme Laboratory in Orléans, France. Her research interest includes decision support and information fusion. She has authored and co-authored well over 31 articles in international journals, 118 in international conferences and proceedings, 15 in books and works of synthesis, 13 papers in national conferences and 20 in conferences in research clusters. She created, co-created and has been the Director of several departments in research and teaching inside and outside of the country.

\title{
1 Background
}

The interpretation of life cycle assessment (LCA) results is difficult especially in the textile domain where the materials, the processes, the logistics policies and even the product usage are various. The optimisation of supply chain scenarios with respect to environmental impacts is rarely obvious. For the same textile product usage, several materials, processes and logistics policies are possible. In this paper, we compare supply chains for a t-shirt made with different raw materials, cotton, polyester or viscose. Actually, we are not only face to a variation of raw materials but also to a variation in processing: fibre production, spinning, wet treatments, production steps, locations and usage. The evaluation shows that each scenario has some environmental impacts where it is better than the other scenarios whereas it is worse related to other impacts. In this case, decision-making is difficult and needs the application of a multiple criteria decision-making (MCDM) method that respects different environmental impacts [global 
warming potential (GWP), human toxicity potential (HTP), eutrophication potential (EP), etc.].

The aim of this paper is to analyse and to select an appropriate MCDM method in order to clarify the values of the life cycle impact assessment (LCIA) and to choose better alternatives in the textile industry. This choice of alternatives should also take into account both the complexity of the textile supply chain and the LCA (Boufateh et al., 2007).

This paper is structured into the following sections. Section 2 gives a brief description of the LCA in the textile field. Then, an overview of MCDM methods used in the environmental context is followed by the selection of an outranking method to fulfil the purpose of the comparative LCA study. Finally, a case study from the textile industry is illustrated in order to show the interest of using MCDM methods.

\section{LCA in the textile field}

The evaluation of environmental impacts of textile products from cradle to grave requires the quantification of all input and output flows along the entire supply chain, the product use and its end of life, as shown in Figure 1. This quantification is the life cycle inventory (LCI). The LCIA is then calculated according to the chemical emissions that are identified during the LCI. The LCA impacts are various: climate change, tropospheric ozone creation, eutrophication, acidification, toxicological aspect, resources depletion, water and land use, or noise. These impacts should be taken into consideration in order to design and optimise a so-called 'green supply chain'.

Figure 1 LCA steps

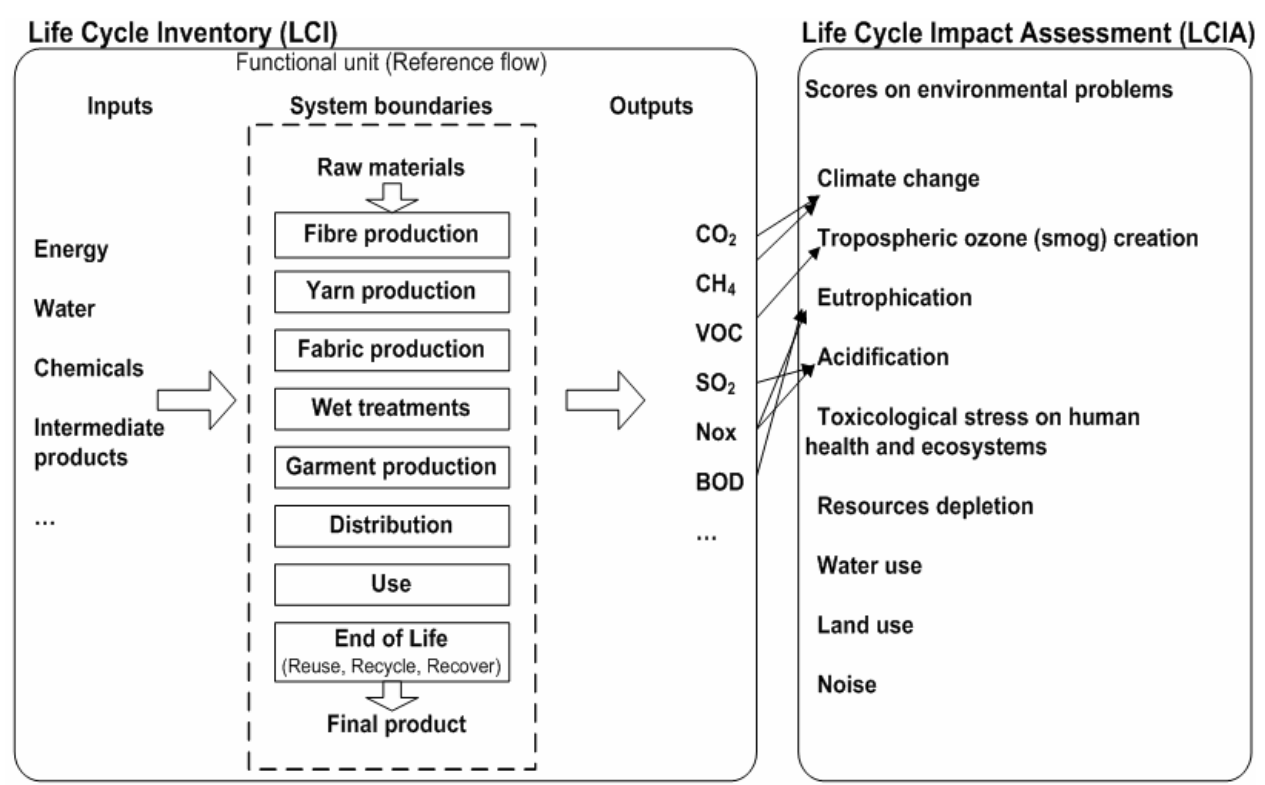


The optimal decision is based on several criteria of different types, characterised with different categories in different units, e.g., eutrophication in $\mathrm{kg}$ phosphate equivalent, GWP in $\mathrm{kg} \mathrm{CO}_{2}$ equivalent, and so on. According to these results, it is not obvious to compare different supply chain alternatives by aggregating the LCIA values into a single score. Here we are face to a MCDM problem.

It is important to mention that many methods of LCIA exist. Their indicators categories are different. When applying the most known methods, we observed some differences in the results related to characterisation models specific to each one. ILCD (2009) detailed the impact categories and the methodologies of calculation of the most used LCIA methods. Here, criteria taken into account are LCIA of outputs calculated using the CML 2001 method (Guinée et al., 2001). This choice is mainly based on the easiness of exploitation of their values and on the fact that indicators categories of CML 2001 cover the majority of impacts that should be assessed in the textile field such as ecotoxicity of water, soil and air. These impacts are well-detailed (Huijbregts et al., $2000,2001)$ and assessed in the 'midpoints' level contrary to other methods, such as eco-indicator 99 where the impacts are grouped into three impact categories: damage to resources, damage to ecosystem, damage to human health and assessed in an 'endpoints' level. Therefore, uncertainty related to this level is avoided when CML 2001 is applied.

\section{MCDM in LCIA}

Many authors compared the existing MCDM methods and proposed guidelines to help choosing an appropriated MCDM method (Guitouni and Martel, 1998). In the context of the environmental assessment, some authors have chosen multicriteria analysis methods to assess environmental impacts (Sarkis, 1998; Caillet, 2003). To interpret the LCIA, few authors used the MCDM methods. Within this framework a protocol of choice based on a classification under categories corresponding to LCA characteristics in general is proposed (Chevalier and Rousseaux, 1999; Benoit and Rousseaux, 2003).

The purpose of this paper is to compare the different features of the textile products assessments and the criteria types; as regards the choice of suitable MCDM methods specific to the LCA in the textile field.

\subsection{Overview of decision analysis methods in LCA}

In the LCA thinking, decision-making aid was first mentioned in the context of weighting factors for the calculations of LCIA. The methods used are multiattribute utility theory (MAUT) and analytical hierarchy process (AHP). Later, decision analysis was recommended in an earlier stage of LCA which is the definition of the goal and scope according to feasible alternatives and impacts categories. Decision analysis was also made in the step of gathering data. Table 1 summarises the recommendation of many authors to use decision analysis methods in LCA stages.

LCA is a tool that collects, organises, and evaluates quantified data useful for decision-making. However, the evaluations are not often clear enough to serve the purpose of comparative LCAs, especially, when we are unable to distinguish the best alternative. 
Table 1 Decision analysis applied in the different stages of LCA

\begin{tabular}{lc}
\hline LCA steps & Authors \\
\hline Goal and scope definition & Miettinen and Hamalainen (1997) \\
Inventory analysis & Werner and Scholz (2002) \\
Impact analysis: & Hertwich (2001) \\
Classification & Chevalier and Rousseaux (1999) \\
Characterisation & Benoit and Rousseaux (2003) \\
Valuation and aggregation & Miettinen and Hamalainen (1997) \\
& Basson and Petrie (1999) \\
& Basson et al. (2000) \\
& Seppala et al. (2002) \\
Interpretation & Seppala (2003) \\
& Le Téno and Mareschal (1998) \\
& Le Téno (1999) \\
\hline
\end{tabular}

\subsection{Aid for interpreting LCIA}

As shown in Figure 1, environmental impacts of product life cycle are classified under different categories (resources depletion, human health, ecosystems and ecological aspects). Their characterisation is based on scientific information (aggregation of different emissions within a single category for each impact). However, the valuation of these impacts still a crucial part in the LCA. Normalisation and weighting still subjective and depend on the preferences of the decision-maker. Since our understanding of environmental processes is ever perfect, we are not able to decide whether and how much products' impacts are serious. Consequently, decision analysis may have misleading conclusions. The LCA thinking consists on a multicriteria tool for a global decision. Interpreting LCIA with a MCDM method fulfils the purpose of the study which is the consideration of several criteria of different types (impacts categories). The aim of this section is to select an appropriate MCDM method. Many different methods for multiple criteria problems can be found in the literature. They can be grouped into three main groups (Vincke, 1989):

- Multi-attribute utility theory such as MAUT, SMART, UTA, TOPSIS, AHP and GP that consist on the aggregation of different points of view in a single function that is then optimised. Instead of their success in the environmental field (Miettinen and Hamalainen, 1997; Sarkis, 1998; Basson et al., 2000; Hertwich, 2001; Seppala et al., 2002; Seppala, 2003; Geldermann and Rentz, 2005), these methods do not fit to our context because they add to the complexity of the study (Boufateh et al., 2007) in establishing the utility function (Roy and Bouyssou, 1993). They may also discard good trade-offs because of compensation and exclusion of incomparability.

- Interactive methods that consist on interactive and iterative exploration of all alternatives. These methods fit to problems with almost infinite number of alternatives and can be merged with the following group. 
- Outranking methods that consist on pairwise comparison of alternatives according to each criterion with introducing indifference and preference thresholds (Bouyssou and Roy, 1987). These thresholds translate comparisons on an axis of signification in order to structure a global preference between alternatives without compensation (partial aggregation). For each relationship, an index called degree of credibility of outranking quantifies the dominance of one alternative over another. Among the advantages of these methods we highlight the possible relationships that are indifference, incomparability or preference.

Decision support system should be more intuitive and simpler. In addition to their simple use, outranking methods are characterised by a good degree of pragmatism in the decisional context of textile LCA. That is why we suggest them to support decision-makers in this framework. The most popular methods are:

- Elimination et choix traduisant la realité (ELECTRE) which was conceived by Roy (1968). This MCDM method is able to model a real-world multicriteria situation by establishing the possible relationships in a realistic comparison: preference, indifference and incomparability by using two thresholds called discordance and concordance. The concordance index represents the degree to which an alternative $a$ is better than an alternative $b$, whereas the discordance index reflects the degree to which alternative $a$ is worse than alternative $b$. Many versions of ELECTRE exist. They are operationally different but they are all based on the same fundamental concepts. In the LCA field, ELECTRE was used by Basson et al. (2000), Caillet (2003) and Basson and Petrie (2007).

- Preference ranking organisation method for enrichment evaluation I (PROMETHEE I) (partial ranking) and preference ranking organisation method for enrichment evaluation II (PROMETHEE II) (complete ranking) were developed by Brans et al. (1984). This MCDM method is also able to incorporate the fuzzy nature of decision-making by using two thresholds called preference and indifference. PROMETHEE is used in LCA by Le Téno and Mareschal (1998), Le Téno (1999), Geldermann (2000), Caillet (2003) and Geldermann and Rentz (2005).

\section{Study cases from the textile industry}

The aim of this paper is to support decision-makers in choosing the best scenario of a 'green textile supply chain' for an eco-designer or an eco-consumer. The case study illustrates the comparison of three alternatives of a t-shirt life cycle. The first alternative (VI) is a t-shirt made of viscose fibres, the second alternative (PES) is made of polyester fibres and the last alternative (CO) is made of cotton fibres. The differences between these alternatives concern the material, the textile processes that are specific to each material, the production location of fibres and the maintenance in use phase that depends on the t-shirt material.

After evaluating the environmental impacts of three alternatives of a t-shirt life cycle, an outranking method is applied to compare the results of the LCIA. The LCA study was conducted following the principals of the standard series ISO 14040 (AFNOR, 2001). The criteria are the environmental impacts of the outputs (Figure 2): EP, GWP, ozone layer depletion potential (ODP), acidification potential (AP), fresh water aquatique 
eco-toxicity potential (FAETP), HTP, marine aquatique eco-toxicity potential (MAETP), photochemical ozone creation potential (POCP), terrestic eco-toxicity potential (TETP) and water consumption (WC). These criteria are calculated by using the method CML 2001 (Guinée et al., 2001).

Figure 2 LCIA of three alternatives of t-shirt (see online version for colours)

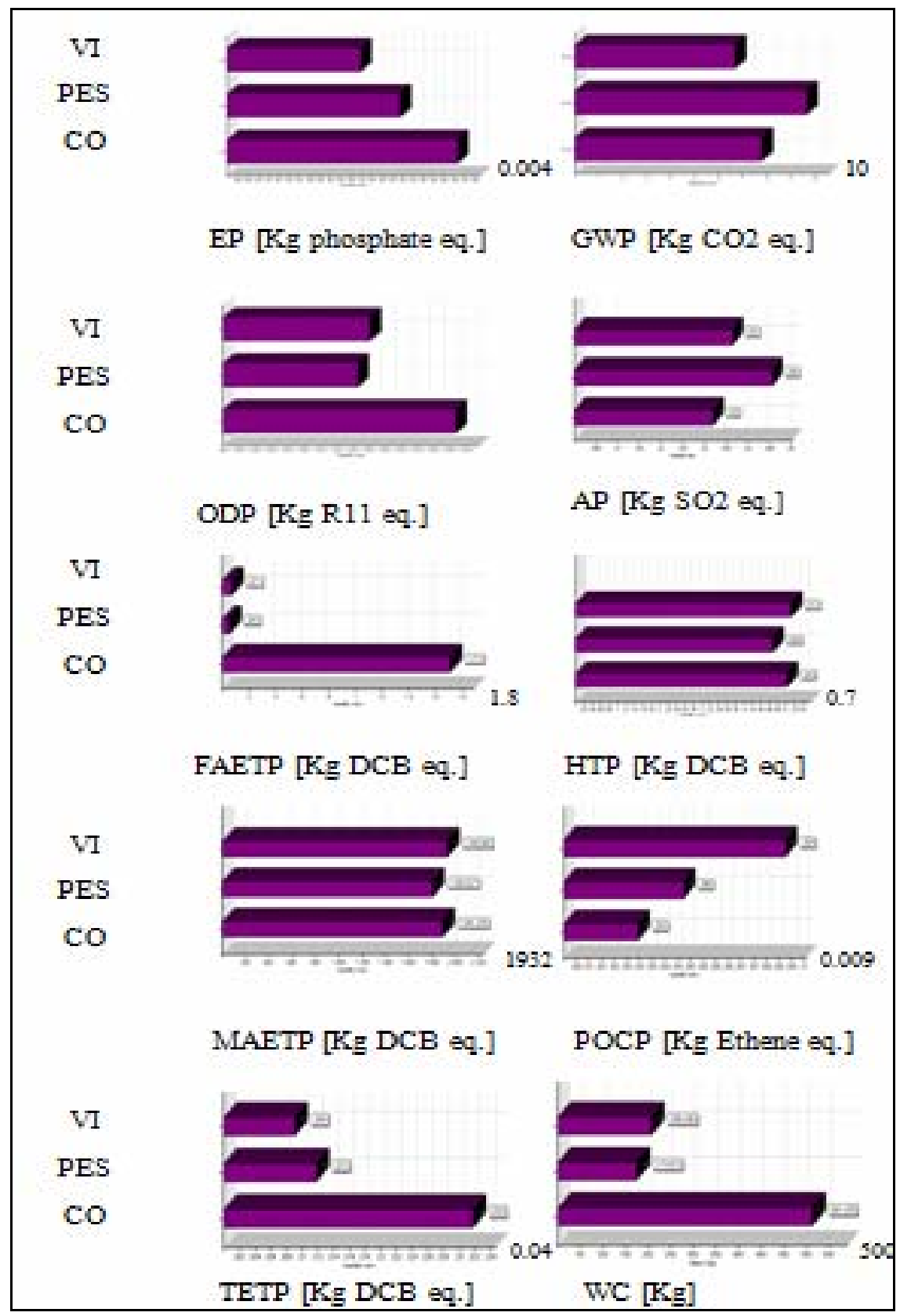

Notes: Viscose (VI), polyester (PES) and cotton (CO) 
Regarding the few number of alternatives, an eye analysis could show the number of times where each alternative VI, PES and CO is the first (the smallest value of environmental impact), the second or the third as shown in Table 2.

Table 2 Number of criteria allowing each alternative to be first, second or third in ranking

\begin{tabular}{lccc}
\hline & $V I$ & $P E S$ & $C O$ \\
\hline First & 3 & 5 & 2 \\
Second & 5 & 3 & 1 \\
Third & 2 & 2 & 7 \\
\hline
\end{tabular}

This quick analysis shows that VI is strictly preferred to CO while PES is weakly preferred to VI. A deeper analysis shows that VI could be preferred to PES as regards four criteria that are EP, GWP, AP and TETP. The gap between these criteria and the other five criteria that make PES better is not obvious. So the decision may be sensitive to modification of weights of criteria. Then the use of a MCDM method especially outranking methods provides a confirmation. Indeed, the situation of outranking corresponds to the existence of clear and positive reasons that justify either a preference or a presumption of preference (weak preference) for one (identified) of the two actions but without any significant separation established between the situations of strict preference, weak preference and indifference (Roy, 1985).

Regarding multiple criteria in a decision-making problem, situations of 'incomparability' or 'intransitivity' may occur when a human decision-maker is faced to alternatives that he cannot say which he prefers. This may also be due to imperfect data available to assess the situation. Moreover, the indifference and preference between two situations are not necessarily transitive. For example, when we like products $a$ and $\mathrm{b}$ that differ by a certain amount of an ingredient and we like products $b$ and $c$ which differ in the same way, this does not mean that we like both $a$ and $c$. In fact, this indifference hides a situation of weak preference not enough to be felt and expressed. So, preference may be non-transitive (condorcet paradox). French and Belgian schools have introduced the concept of partial aggregation where we simply appreciate the consequences of partially different judgments; this approach is sometimes called 'outranking approach accepting incomparability'. In this approach, we build outranking relationships to represent the preferences of regarding available information.

In the textile field the number of alternatives possible for the same product may be important. For instance, for a cotton t-shirt, there are 320 scenarios of production possible by changing processes in spinning, knitting, pre-treatments, dyeing and finishing. The great number of alternatives adds to the complexity in analysing the gap between criteria values to compare and distinguish the best alternative. So the application of an outranking method fulfils the objective to resolve a decision-making problem regarding environmental issues. Modelling preference in a fuzzy way by using the thresholds of preference and indifference is interesting to reduce uncertainty incorporated in the information available concerning impacts assessment of alternatives.

\subsection{Application of PROMETHEE}

The suggested outranking method is PROMETHEE I for partial ranking. This method directly assesses, on a scale from 0 to 1 , the level of verification of conditions that 
validate the proposal ' $b$ outranks $a$ or $b$ is preferable to $a$ ', leading to define an index of credibility of the proposal. We speak in this case about fuzzy relation (Roy and Bouyssou, 1993). The thresholds of indifference and preference (Bouyssou and Roy, 1987) and the linear function of preference (De Keyser and Peeters, 1996) can take into account the uncertainty (Hyde et al., 2005) in the data of the LCI that Boufateh et al. (2008) mentioned. The decision-making process that we face satisfies the necessary and sufficient conditions defined by Roy and Bouyssou (1993) to make this choice of method for multicriteria decision. At least one of these conditions must be validated which is the case:

1 Among criteria, at least one criterion does not allow translating the difference in values in terms of difference in preferences. It is the case of criteria that are not quantitative.

2 Criteria values cannot be easily expressed in a common unit: as explained in Part 2, the impact categories are characterised in different units, for instance, $\mathrm{EP}$ is calculated in $\mathrm{kg}$ phosphate equivalent while GWP is in $\mathrm{kg} \mathrm{CO}_{2}$ equivalent.

3 The compensation of the disadvantage of one criterion by the advantage of another criterion occurs in complex ways and/or in connection with systems of values that cannot be modelled: because of insufficient knowledge of ecological issues, we are unable to know the severity of an impact compared to another one. For instance, PES is worse that VI as regards the criterion GWP, whereas VI is worse that PES as regards the criterion POCP. Therefore, we cannot establish the traditional relationship of preference between PES and VI as regards both of GWP and POCP criteria.

4 Some of the criteria are pseudo-criteria and it seems desirable to take into account the thresholds of indifference and/or preference associated with them for the global preferences: modelling the preference relationship in a fuzzy way is more realistic. In that case not all the incomparability cases are withdrawn but the information is reliable.

The performance $g$ of a pseudo-criterion is made with two thresholds $q($.$) and p($. establishing three types of relationships: indifference (I), incomparability (Q) and preference (P) between alternatives $a$ and $b$ (Bouyssou and Roy, 1987):

$$
g(b) \geq g(a)=>\left(\begin{array}{ll}
b \mathrm{I}_{\mathrm{g}} a & \text { if } g(b)-g(b) \leq q(g(a)) \\
b \mathrm{Q}_{\mathrm{g}} a & \text { if } q(g(a))<g(b)-g(a) \leq p(g(a)) \\
b \mathrm{P}_{\mathrm{g}} a & \text { if } p(g(a))<g(b)-g(a)
\end{array}\right.
$$

The model used for this example is based on:

- $\mathrm{S}:=\{\mathrm{VI}, \mathrm{PES}, \mathrm{CO}\}$ : Set of three scenarios of t-shirt.

- $\mathrm{I}:=\{$ EP, GWP, ODP, AP, FAETP, HTP, MAETP, POCP, TETP, WC $\}$ : Set of criteria relevant for the decision.

- F: Linear preference function with two thresholds (indifference and preference). A careful sensitivity analysis was done for the determination of these thresholds. The 
final choice was based on the daily average quantities of impacts by person in the world as of 2007 (PE INTERNATIONAL, 2007) (latest data) and the share of textile field in the environmental impacts of private consumption $(2 \%-10 \%)$ (Tukker et al., 2006).

- W: Criteria weights. Weighting is as important as the determination of thresholds because it affects roughly the results (see Figures 3, 5 and 6).

The results given in Figure 3 show that PES is preferable to VI and VI is preferable to $\mathrm{CO}$ if we consider that all the impacts are equal as regards their countenance. This judgment was not obvious when analysing LCIA results without a MCDM method.

Figure 3 LCIA interpretation of alternatives (CO-PES-VI) using PROMETHEE I (see online version for colours)

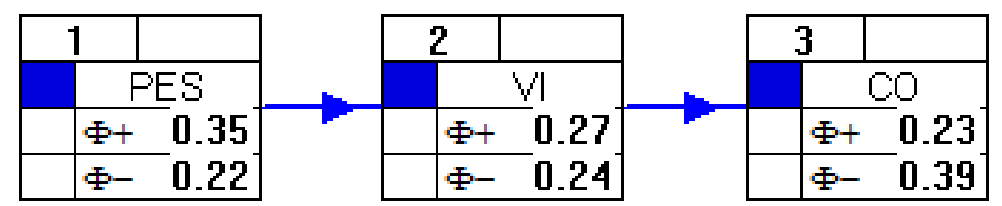

PROMETHEE is also chosen for the simplicity of the exploitation of results. The GAIA plan (Mareschal and Brans, 1988) provides a geometric representation of alternatives and criteria on the basis of principal component analysis. The projection of the vector of weights (the axis from the centre to the point pi with o symbol) indicates the direction of trade-off resulting from the weighting given to criteria (Figure 4). By conducting a sensitivity analysis of the weighting, the orientation of the axis changes according to the decision (Figure 6). The results as shown in Figures 3 and 4 were based on equal weights of criteria.

Figure 4 GAIA plan of criteria and alternatives (see online version for colours)

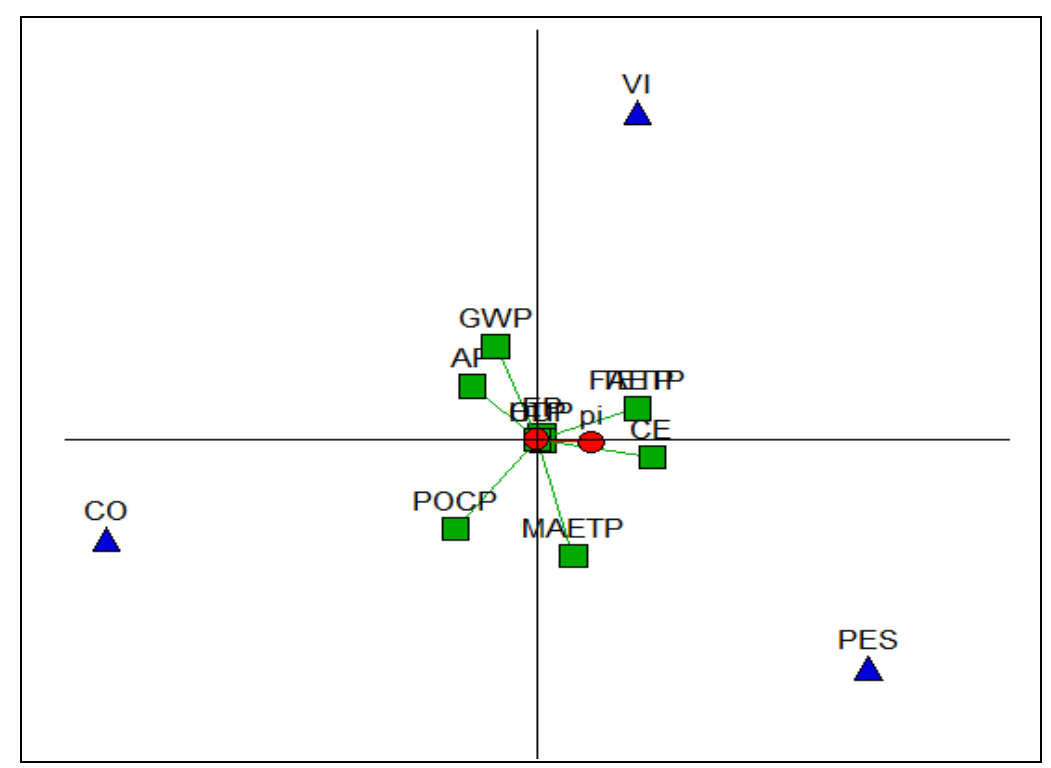


The next figures show that weighting is a crucial issue in environmental impacts optimisation and it is still subjective. For instance, if we estimate that GWP is twice more important that the other impacts, the results change as given below.

Figure 5 GAIA plan of criteria and alternatives and outranking results showing the effect of weighting variation (see online version for colours)

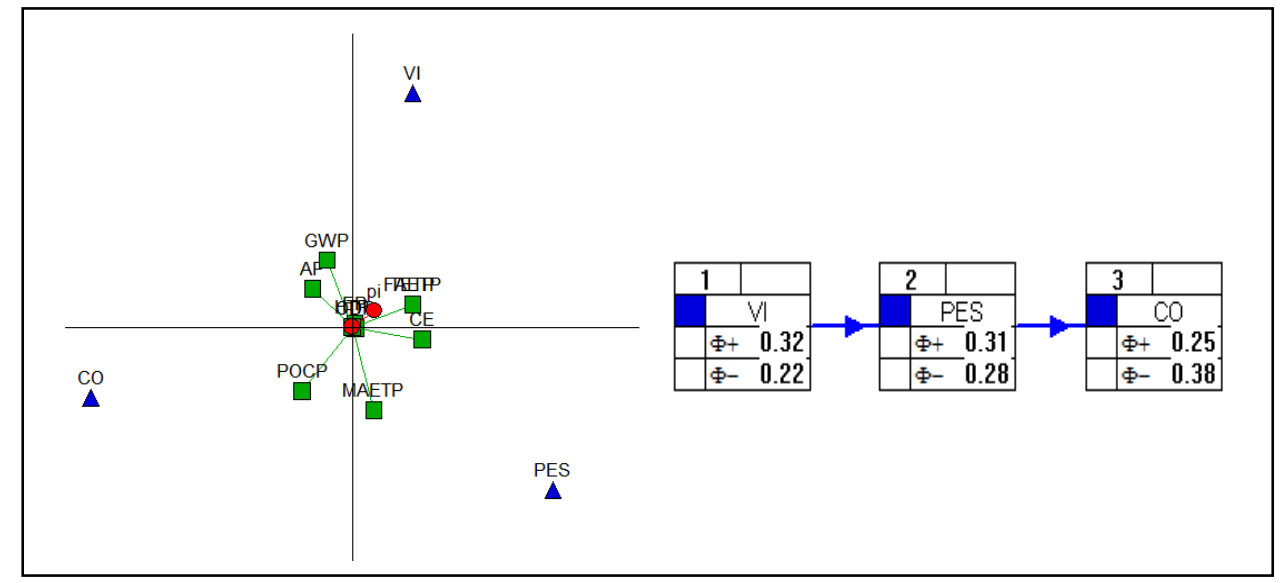

Note: Weight $(\mathrm{GWP})=2$

Figure 6 GAIA plan of criteria and alternatives and outranking results showing the weighting variation according to the account of the total impacts (see online version for colours)

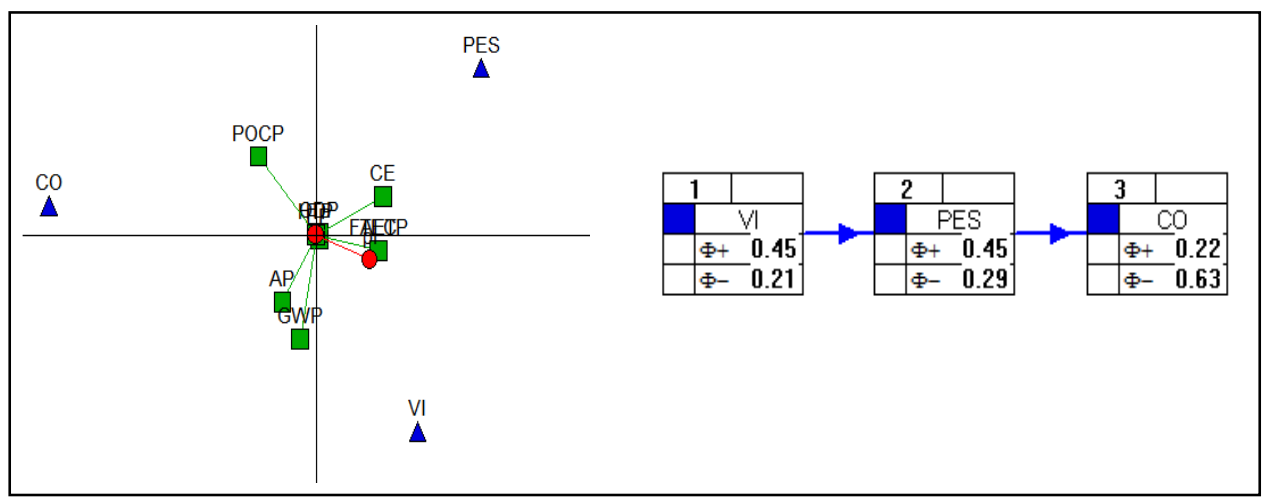

\subsection{Sensitivity analysis of weighting}

Weighting reflects decision-makers' points of view and depends on their preferences. To avoid subjectivity in defining criteria weights, we use the percentage account of criteria values in the daily pollution of one person in the world and its account in the total. The percentage account is the average of evaluated alternatives (CO: $t$-shirt in cotton, VI in viscose and PES in polyester). For instance, in GWP, the average daily pollution is 17.16 $\mathrm{kg} \mathrm{CO}$ equiv./person, the total impact of cotton t-shirt (CO) is $7.79 \mathrm{~kg} \mathrm{CO}_{2}$ equiv., the total impact of polyester t-shirt (PES) is $9.22 \mathrm{~kg} \mathrm{CO}_{2}$ equiv. and the total impact of viscose t-shirt (VI) is $6.68 \mathrm{~kg} \mathrm{CO}_{2}$ equiv. (Figure 2). The account of the life cycle 
modelled in the LCA study above in GWP is $45.41 \%$ by person equivalent by day for the $\mathrm{t}$-shirt in cotton $(\mathrm{CO})$. This represents $1.48 \%$ of the total impacts of the alternative $(\mathrm{CO})$. For the t-shirt in polyester (PES), the account of GWP is $53.73 \%$ of GWP caused by person and is $2.27 \%$ of the total impacts of the t-shirt (PES). For the t-shirt in viscose (VI), the account of GWP is $38.96 \%$ by person and is $1.51 \%$ of the total impacts of the t-shirt (CO). So, the weight of GWP considered is the average of the accounts of the total impacts which is $1.75 \%$. The results show that VI is preferable to PES and PES is preferable to $\mathrm{CO}$.

All the results show that the t-shirt in cotton is the worst scenario. The preference relationship between the scenarios PES and VI is sensitive to the weighting.

\subsection{Application of ELECTRE}

ELECTRE is a popular outranking method. Among the methods ELECTRE, we suggest to use ELECTRE III which is based on a fuzzy representation of preferences in the presence of multiple criteria. It has almost similar approach as PROMETHEE. The difference between these outranking methods consists on the translation of the information of the measured criteria value (constant thresholds in PROMETHEE and proportional thresholds in ELECTRE). The reasons to choose this MCDM method are the same as for PROMETHEE.

Calculations made according the ELECTRE III, represented in Figure 7, show that the results are the same (VI is preferable to PES, PES is preferable to CO) for the main influencing criteria shown in Figure 6 with the same weighting and the same thresholds.

Figure 7 Results of LCIA interpretation using ELECTRE III (see online version for colours)

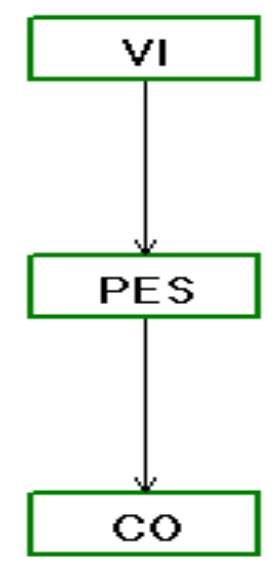

\section{Conclusions}

The interpretation of the LCA results in the textile field should be aided with the application of a MCDM method that must be specific to the decision process (Jolly, 2009). The purpose of decision-making aid in this example is not to make judgments about fibres but it is to provide a greater understanding of the situation and to show how 
the results of LCA could be interpreted through a MCDA method. Outranking methods fit decisional context of LCA in the textile industry for many reasons namely the simplicity of use, the relationships that respect incomparability and indifference, the partial aggregation avoiding any compensation that may discard good trade-offs and finally the fuzzy representation of preferences according to indifference and preference thresholds in order to reduce the uncertainty related to the LCIA results due to the uncertainties of LCI. In addition to that this method considers multiple pseudo-criteria of different types.

In order to insure reliable results, the robustness of the decision should be evaluated. Sensitivity analysis could help decision-maker to define intervals stabilities of criteria weights.

\section{References}

AFNOR (2001) 'Management de l'environnement - management environnemental des produits', 4ème édition, Tome 2, AFNOR 2001-2ème tirage 2002:

NF EN ISO 14040: Septembre 1997 'Management environnemental - analyse du cycle de vie - principes et cadre'.

NF EN ISO 14041: Décembre 1998 'Management environnemental - analyse du cycle de vie - définition de l'objectif et du champ d'étude et analyse de l'inventaire'.

NF EN ISO 14042: Mai 2000 'Management environnemental - analyse du cycle de vie evaluation de l'impact du cycle de vie'.

NF EN ISO 14043: Mai 2000 'Management environnemental - analyse du cycle de vie interprétation du cycle de vie'.

Basson, L. and Petrie, J. (2007) 'A critical systems approach to decision support for process engineering', Computers and Chemical Engineering, Vol. 31, pp.876-888.

Basson, L. and Petrie, J.G. (1999) 'Making during early stages of a project life cycle: roles for multiple criteria decision analysis, life cycle assessment and ecological risk assessment', SETAC 20th Annual Meeting, Philadelphia, 14-18 November.

Basson, L., Perkins, A.R. and Petrie, J.G. (2000) 'The evaluation of pollution prevention alternatives using non-compensatory multiple criteria decision analysis methods', Annual Meeting of the American Institute of Chemical Engineers (AIChE), Los Angeles, CA, AIChE Manuscript Center, New York, Presentation Record 230c.

Benoit, V. and Rousseaux, P. (2003) 'Aid for aggregating the impacts in life cycle assessment', International Journal LCA, Vol. 8, No. 2, pp.74-82.

Boufateh, I., Perwuelz, A., Rabenasolo, B. and Jolly, A.M. (2007) 'Optimization of environmental and social criteria in the textile supply chain: European state of the art and perspectives of research', Proceedings of the International Conference on Product Lifecycle Management PLM'07 - Assessing the Industrial Relevance, Product Lifecycle Management - Special Publication 3, pp.667-676.

Boufateh, I., Perwuelz, A., Rabenasolo, B. and Jolly, A.M. (2008) 'Life cycle assessment: data availability, reliability and robustness in textile industry', Working Towards Change: Academy and Industry Together, 8th AUTEX Conference, Biella, Italy.

Bouyssou, D. and Roy, B. (1987) 'La notion de seuils de discrimination en analyse multicritère', INFOR, Vol. 25, No. 4, pp.302-313.

Brans, J.P., Mareschal, B. and Vincke, P. (1984) 'PROMETHEE: a new family of outranking methods in multicriteria analysis', in J.P. Brans (Ed.): Operational Research'84, pp.408-421, Elsevier Science Publishers B.V., North-Holland.

Caillet, R. (2003) 'Analyse multicritère: etude de comparaison des méthodes existantes en vue d'une application en analyse de cycle de vie', Cahier Cirano, 2003s-53. 
Chevalier, J. and Rousseaux, P. (1999) 'Classification in LCA: building of a coherent family of criteria', International Journal LCA, Vol. 4, No. 6, pp.352-356.

De Keyser, W. and Peeters, P. (1996) 'Theory and methodology - a note on the use of PROMETHEE multicriteria methods', European Journal of Operational Research, Vol. 89, pp.457-461.

Geldermann, J. (2000) 'Fuzzy outranking for environmental assessment. Case study: iron and steel making industry', Fuzzy Sets and Systems, Vol. 115, pp.45-65.

Geldermann, J. and Rentz, O. (2005) 'Multicriteria analysis for the assessment of environmentally relevant installations', Journal of Industrial Ecology.

Guinée, J.B. (final Ed.), Gorrée, M., Heijungs, R., Huppes, G., Kleijn, R., De Koning, A., Van Oers, L., Wegener Sleeswijk, A., Suh, S., Udo de Haes, H.A., De Bruijn, H., Van Duin, R., Huijbregts, M.A.J., Lindeijer, E., Roorda, A.A.H. and Weidema, B.P. (2001) 'Life cycle assessment; an operational guide to the ISO standards; Parts 1 and 2', Ministry of Housing, Spatial Planning and Environment (VROM) and Centre of Environmental Science (CML), Den Haag and Leiden, The Netherlands.

Guitouni, A. and Martel, J.M. (1998) 'Tentative guidelines to help choosing an appropriate MCDA method', European Journal of Operational Research, Vol. 109, pp.501-521.

Hertwich, E.G. (2001) 'A decision analytic framework for impact assessment, Part 1: LCA and decision analysis', International Journal LCA, Vol. 6, No. 1, pp.5-12.

Huijbregts, M.A.J., Guinée, J.B. and Reijnders, L. (2001) 'Priority assessment of toxic substances in life cycle assessment. Part III: export of potential impact over time and space', Chemosphere, Vol. 44, pp.59-65.

Huijbregts, M.A.J., Thissen, U.J.B., Guinée, T., Jager, D., Kalf, D., Van de Meent, A.M.J., Ragas, A., Sleeswijk, W. and Reijnders, L. (2000) 'Priority assessment of toxic substances in life cycle assessment. Part I: calculation of toxicity potentials for 181 substances with nested multi-media fate, exposure and effects model USES-LCA', Chemosphere, Vol. 41, pp.541-573.

Hyde, K., Maier, H.R. and Colby, C. (2005) 'Incorporating uncertainty in the PROMETHEE MCDA method', Journal of Multi-Criteria Decision Analysis, Vol. 12, Nos. 4-5, pp.245-259.

International Reference Life Cycle Data System (ILCD) (2009) 'Background document: analysis of existing environmental impact assessment methodologies for use in life cycle assessment (LCA)', Draft for public consultation, European Commission Joint Research Centre Contract No. 383163 F1SC.

Jolly, A.M. (2009) 'Multicriteria decision making for product design in the frame of sustainable development', Supply Chain Forum: An International Journal, Vol. 10, No. 1, pp.52-60.

Le Téno, J.F. (1999) 'Visual data analysis and decision support methods for non-deterministic LCA', International Journal of Life Cycle Assessment, Vol. 4, No. 1, pp.41-47.

Le Téno, J.F. and Mareschal, B. (1998) 'An interval version of PROMETEE for the comparison of building products' design with ill-defined data on environmental quality', European Journal of Operational Research, Vol. 109, pp.522-529.

Mareschal, B. and Brans, J.P. (1988) 'Geometrical representations for MCDA', European Journal of Operational Research, Vol. 33, pp.54-64.

Miettinen, P. and Hamalainen, R.P. (1997) 'How to benefit from decision analysis in environmental life cycle assessment (LCA)', European Journal of Operational Research, Vol. 102, pp.279-294.

PE INTERNATIONAL, GaBi 4 (2007) 'Software and database for life cycle engineering', PE INTERNATIONAL GmbH, Stuttgart, April.

Roy, B. (1968) 'Classement et choix en présence de points de vue multiples: la méthode ELECTRE', Revue Française d'Informatique et de Recherche Opérationnelle, Vol. 8, pp.57-75.

Roy, B. (1985) Méthodologie Multicritère d'Aide à la Décision, Economica, Paris. 
Roy, B. and Bouyssou, D. (1993) Aide Multicritère à la Décision: Méthodes et Cas, Editions Economica, Paris.

Sarkis, J. (1998) 'Evaluating environmentally conscious business practices', European Journal of Operational Research, Vol. 107, pp.159-174.

Seppala, J. (2003) 'Life cycle impact assessment based on decision analysis', Doctoral thesis, Helsinki University of Technology, Department of Engineering Physics and Mathematics Systems Analysis Laboratory.

Seppala, J., Basson, L. and Norris, G.A. (2002) 'Decision analysis frameworks for life cycle impact assessment', Journal of Industrial Ecology, Vol. 5, No. 4, pp.46-68.

Tukker, A., Huppes, G., Guinée, J., Heijungs, R., De Koning, A., Van Oers, L., Suh, S., Geerken, T., Van Holderbeke, M., Jansen, B., Nielsen, P., Eder, P. and Delgado, L. (2006) 'Environmental impact of products (EIPRO) - analysis of the life cycle environmental impacts related to the final consumption of the EU-25', Main report, IPTS/ESTO project, European Commission, Joint Research Centre, EUR 22284.

Vincke, P. (1989) L'aide Multicritère à la Décision, Editions Ellipses, Bruxelles, Editions de l'Université de Bruxelles, Paris.

Werner, F. and Scholz, R.W. (2002) 'Ambiguities in decision-oriented life cycle inventories', International Journal of Life Cycle Assessment, Vol. 7, No. 6, pp.330-338. 